\title{
Cytochalasin $\mathrm{H}$ isolated from mangrove-derived endophytic fungus inhibits epithelial-mesenchymal transition and cancer stemness via YAP/TAZ signaling pathway in non-small cell lung cancer cells
}

\author{
Zihan $\mathrm{Xiu}^{1 \#}$, Jiao Liu${ }^{1 \#}$, Xin $\mathrm{Wu}^{2,3}$, Xiangyong $\mathrm{Li}^{1}$, Sanzhong $\mathrm{Li}^{1}$, Xiaofeng $\mathrm{Wu}^{1}$, Xiaohua $\mathrm{Lv}^{2}$, Hua $\mathrm{Ye}^{2,3}$ and \\ Xudong Tang $1,2,3,4$ \\ 1. Collaborative innovation center for antitumor active substance research and development, Institute of Biochemistry and Molecular Biology, Guangdong \\ Medical University, Zhanjiang 524023, P.R. China. \\ 2. Guangdong Key Laboratory for Research and Development of Natural Drugs, Marine Medical Research Institute of Guangdong Zhanjiang, Department of \\ Pharmacology, Guangdong Medical University, Zhanjiang 524023, P.R. China. \\ 3. Southern Marine Science and Engineering Guangdong Laboratory (Zhanjiang), Zhanjiang 524023, P.R. China. \\ 4. Guangdong Provincial Key Laboratory of Medical Molecular Diagnostics, Dongguan Key Laboratory of Medical Bioactive Molecular Developmental and \\ Translational Research, Guangdong Medical University, Dongguan 523808, P.R. China.
}

\#These authors contributed equally to this work.

$\square$ Corresponding author: Xudong Tang, MD, PhD, Collaborative innovation center for antitumor active substance research and development, Guangdong Medical University, 2 Wenming Donglu, Xiashan, Zhanjiang, Guangdong 524023, P.R. China. Phone: 86-759-2388581; Fax: 86-759-2284104; E-mail: tangxudong2599@126.com; txd@gdmu.edu.cn.

(c) The author(s). This is an open access article distributed under the terms of the Creative Commons Attribution License (https://creativecommons.org/licenses/by/4.0/). See http:/ /ivyspring.com/terms for full terms and conditions.

Received: 2020.07.09; Accepted: 2020.12.01; Published: 2021.01.01

\begin{abstract}
Our previous studies have isolated cytochalasin $\mathrm{H}(\mathrm{CyH})$ from endophytic fungus derived from mangrove and found that $\mathrm{CyH}$ induced apoptosis and inhibited migration and angiogenesis in non-small cell lung cancer (NSCLC) cells. In this study, we further investigated the effect of $\mathrm{CyH}$ on epithelial-mesenchymal transition (EMT) and cancer stemness of A549 and NCl-H460 NSCLC cells and the underlying mechanisms, especially the role of YAP/ TAZ signaling pathway in the process. Our results showed that $\mathrm{CyH}$ significantly inhibited invasive ability and the sphere formation of NSCLC cells. The expression of E-cadherin, an EMT epithelial marker, was obviously up-regulated, while the expression of Vimentin and $\mathrm{N}$-cadherin, the EMT mesenchymal markers, was dramatically down-regulated by $\mathrm{CyH}$ treatment in NSCLC cells. Moreover, the expression of EMT-associated transcription factors including Slug, Twist1, and Snail 1 and stemness markers including Nanog, Sox-2, and Oct-4 was significantly down-regulated by $\mathrm{CyH}$ treatment in NSCLC cells. Additionally, CyH significantly down-regulated YAP and TAZ expression and up-regulated LAST1/2 and MST1/2 expression, and $\mathrm{CyH}$ inhibited the interaction between YAP and TEAD. Furthermore, YAP knockdown abolished the effect of $\mathrm{CyH}$ on the expression of EMT- and stemness-related markers in NSCLC cells. Taken together, these results suggest that CyH inhibits EMT and cancer stemness of NSCLC cells via the regulation of YAP/TAZ signaling pathway.
\end{abstract}

Key words: cytochalasin $\mathrm{H}(\mathrm{CyH})$; epithelial-mesenchymal transition (EMT); cancer stemness; YAP/TAZ; non-small cell lung cancer (NSCLC); mangrove

\section{Introduction}

Lung cancer is the leading cause of cancerrelated mortality (18.4\% of the total cancer-related mortality) in both sexes combined [1]. Non-small cell lung cancer (NSCLC) comprises approximately 85\% of lung cancer cases [2]. NSCLC patients with the early-stage are treated by surgery, but recurrence and metastasis are very common at the stage I of NSCLC [2]. Chemotherapeutic agents, such as gemcitabine, platinum compounds, and taxanes, can improve 
survival to a limited extent, but the overall survival rates of NSCLC patients remain low due to recurrence and metastasis $[2,3]$.

Epithelial-mesenchymal transition (EMT) can promote recurrence and metastasis of NSCLC [4,5]. EMT, the loss of epithelial phenotype and the gain of mesenchymal phenotype, is essential for the migratory and invasive capabilities of NSCLC $[6,7]$. Most recently, Lafuente-Sanchis et al. found that the molecular EMT status of micrometastatic sentinel lymph nodes could be regarded as an independent prognosis predictor at the early stage of NSCLC patients [8]. Moreover, Matsubara et al. also demonstrated that EMT was a poor prognosis predictor for the patients with stage IA lung adenocarcinoma, and EMT status might be considered as an indicator for administering adjuvant therapy [9]. EMT can generate cells with properties of stem cells characterized by enhancing the expression of stemness-related markers [10]. Therefore, the inhibitors of EMT and stemness may be promising drugs for the treatment of NSCLC.

Accumulating evidence demonstrates that Yesassociated protein (YAP)/transcriptional coactivator with PDZ-binding motif (TAZ) signaling pathway is involved in mediating EMT and cancer stemness [11-15]. YAP and TAZ, two homologous transcriptional coactivators, are the final effectors of the Hippo signaling pathway [16]. When the Hippo signaling pathway opens, one core kinase MST1/2 can phosphorylate and activate another core kinase LATS1/2. Then the activated LATS1/2 can phosphorylate YAP/TAZ and inactivate YAP/TAZ activity, inhibiting YAP/TAZ transfer to nucleus. Finally, YAP/TAZ in cytoplasm can bind to 14-3-3 or subject to proteasomal degradation $[17,18]$. By contrast, when the Hippo signaling pathway closes, MSAT1/2 and LATS1/2 can be inactivated, leading to the inhibition of YAP/TAZ phosphorylation. Subsequently, the dephosphorylated YAP/TAZ can translocate to nucleus and bind to TEAD $[17,18]$, enhancing TEAD-mediated transcription of the downstream genes and regulating the expression of the target genes such as EMT- and stemness-related genes. YAP/TAZ signaling pathway, activated in multiple human cancers, promotes cancer initiation, progression, and metastasis. Moreover, the increased expression or activation of $\mathrm{YAP} / \mathrm{TAZ}$ is related to a poor prognosis $[19,20]$. Specially, YAP/TAZ is a potential target for the therapy of squamous cell carcinoma including NSCLC $[18,21]$. Therefore, the inhibition of YAP/TAZ is an important strategy for NSCLC therapy.

Mangroves grow in the salt-tolerant ecosystems with high biodiversity, and the abundance and diversity of mangrove resources provide the great potential for the discovery of new compounds [22]. In recent years, multiple potential anticancer compounds have been found from mangrove-derived endophytic fungi [22-25]. In our previous study, we have isolated cytochalasin $\mathrm{H}(\mathrm{CyH})$ from endophytic fungus Phomopsis liquidambari derived from mangrove, which could induce apoptosis and inhibit migration and angiogenesis in NSCLC cells both in vitro and in vivo [26,27]. Tumor angiogenesis can cause EMT that generates cells with stemness properties [10]. However, the effect of $\mathrm{CyH}$ on EMT and cancer stemness still remains unclear.

In this study, to the best of our knowledge, we found for the first time that $\mathrm{CyH}$ inhibited EMT and cancer stemness via the regulation of YAP/TAZ signaling pathway in A549 and NCI-H460 NSCLC cells. These findings indicate that $\mathrm{CyH}$ may be as a potential agent for the prevention and treatment of NSCLC.

\section{Materials and methods}

\section{Drug and reagents}

$\mathrm{CyH}$ (purity $>98 \%$ by HPLC) was extracted from the secondary metabolites of mangrove-derived endophytic fungus Phomopsis liquidambari by our lab [26]. CyH was dissolved in $0.1 \%$ DMSO at $1 \mathrm{mM}$ and diluted into different concentrations with culture medium. Recombinant human FGF-basic (bFGF) and recombinant human EGF were obtained from PeproTech Technology (New Jersey, CA, USA). Mouse anti-human YAP (1:1000 dilution; cat. no. 12395), and rabbit anti-human Phospho-YAP (p-YAP, Ser127, 1:1000 dilution; cat. no. 13008 ), LATS1 (1:1000 dilution; cat. no. 3477), LATS2 (1:1000 dilution; cat. no. 5888), MST1 (1:1000 dilution; cat. no. 3682), MST2 (1:1000 dilution; cat. no. 3952), TAZ (1:1000 dilution; cat. no. 3418), N-Cadherin (1:1000 dilution; cat. no. 13116), Vimentin (1:1000 dilution; cat. no. 5741), Snail1 (1:1000 dilution; cat. no. 3879), Slug (1:1000 dilution; cat. no. 9585), Twist1 (1:1000 dilution; cat. no. 46702), Sox2 (1:1000 dilution; cat. no. 14962), Oct-4A (1:1000 dilution; cat. no. 2750), Nanog (1:1000 dilution; cat. no. 4903), and TEAD (1:1000 dilution; cat. no. 12293) primary antibodies were purchased from Cell Signaling Technology (Danvers, MA, USA). Mouse anti-human E-Cadherin antibody (1:1000 dilution; cat. no. 4903) was purchased from Millipore Technology (Boston, MA, USA). Goat-anti rabbit-HRP (1:2000 dilution; cat. no. 7074S) and goat-anti mouse-HRP (1:2000 dilution; cat. no. 7076S) secondary antibodies and rabbit anti-human IgG (1:1000 dilution; cat. no. 4096) were obtained from Cell Signaling Technology (Danvers, MA, USA). One Step SYBR ${ }^{\circledR}$ PrimeScript $^{\circledR}$ 
RT-qPCR kit (No. DRR086A) was from TaKaRa Biotechnology Co., Ltd. (Dalian, China). BD Matrigel $^{\mathrm{TM}}$ Basement Membrane Matrix High Concentration (No. 354248) was from BD Biosciences (Bedford, MA, USA). Protein A Magnetic Beads were from Cell Signaling Technology (Danvers, MA, USA). Lipofectamine 3000 transfection reagent was from Invitrogen (Carlsbad, CA, USA).

\section{Cell lines and cell culture}

Human A549 and NCI-H460 NSCLC cell lines were purchased from ATCC (Rockville, MD, USA) and the Chinese Academy of Sciences Cell Bank of Type Culture Collection (Shanghai, China), respectively. A549 and NCI-H460 cells were grown in RPMI-1640 media containing 10\% fetal bovine serum (FBS) in a $5 \% \mathrm{CO}_{2}$ incubator at $37^{\circ} \mathrm{C}$. All cells used in this study were in the logarithmic phase of growth.

\section{Invasion assay}

The transwell chambers with $8 \mu \mathrm{m}$ pore (Corning, NY, USA) were pre-coated with Matrigel that was diluted with serum-free medium at 1:8 ratio. A549 and NCI-H460 cells $\left(8.0 \times 10^{5}\right)$ were pretreated with $\mathrm{CyH}(0,0.05,0.1,0.2,0.4$, and $0.8 \mu \mathrm{M})$ for $16 \mathrm{~h}$. Afterwards, the treated cells were washed three times with PBS and then the washed cells were plated on the top of each chamber, and the medium containing $20 \%$ FBS was put in the lower chamber as a chemoattractant. $36 \mathrm{~h}$ incubation later, the cells that did not pass through the filter were removed by a cotton swab and the cells that pass through the filter were stained with $0.1 \%$ crystal violet. The invasive cells were counted at least 5 randomized fields under a microscope and the average invasive cell number per field was calculated.

\section{Sphere formation assays}

A549 and NCI-H460 cells were treated with $\mathrm{CyH}$ at $1.51 \mu \mathrm{M}$ for $16 \mathrm{~h}$. Afterwards, the treated cells were washed three times with PBS, and then the washed cells (5000/well) were seeded into 6-well ultra-low attachment cluster plates (Corning, NY, USA) and grown in serum-free DMEM/F12 medium (Invitrogen, Carlsbad, CA, USA) containing $20 \mathrm{ng} / \mathrm{ml}$ bFGF, $20 \mathrm{ng} / \mathrm{ml}$ EGF, 2\% B27, 0.4\% BSA, and $5 \mu \mathrm{g} / \mathrm{ml}$ insulin. Two weeks later, the formation of spheres was photographed and the number of the spheres was counted.

\section{YAP- siRNA transfection}

One day before transfection, the cells were seeded into a 6-well plate at $50 \%$ confluence without antibiotics. The YAP-siRNA (5'-GCAUCUUCGACAG UCUUC- UTT-3') was synthesized by Sangon Biotech (Shanghai, China). Non-specific siRNA (NS-siRNA) was used as a control. The siRNA transfection was performed using Lipofectamine 3000 according to the manufacturer's instructions.

\section{Western blotting}

The method was as described previously [26,27]. Briefly, A549 and NCI-H460 cells were respectively treated with different concentrations $(0,1.51,3.13$, $6.25,12.5$, and $25 \mu \mathrm{M}$ ) of $\mathrm{CyH}$ for $16 \mathrm{~h}$. Afterwards, the cells were lysed on ice with RIPA lysis buffer (Beyotime Institute of Biotechnology, Shanghai, China) containing protease inhibitors for $1 \mathrm{~h}$. The lysates were ultra-sonicated and centrifuged at 12,000 rpm for $10 \mathrm{~min}$. Protein concentration was detected by the BCA protein assay. The protein samples $(100 \mu \mathrm{g})$ were run on $10 \%$ SDS-PAGE and transferred to PVDF membranes. After being blocked with $5 \%$ non-fat milk or BSA for more than $2 \mathrm{~h}$ at room temperature, the membranes were respectively incubated overnight at $4{ }^{\circ} \mathrm{C}$ with specific primary antibodies against E-cadherin, N-cadherin, Vimentin, OCT-4, SOX-2, Nanog, YAP, p-YAP, TAZ, LATS1/2, and MST1/2 (1:1000), followed by incubation for $1 \mathrm{~h}$ with HRP-conjugated secondary antibodies (1:2000). The signals were examined by ECL reagents and the density was analyzed by ImageJ software [26,27].

\section{RT-qPCR}

The method was as described previously $[27,28]$. Briefly, A549 and NCI-H460 cells were respectively treated with $\mathrm{CyH}(0,1.51,3.13,6.25,12.5$, and $25 \mu \mathrm{M})$ for $16 \mathrm{~h}$. Total RNA in the treated and untreated cells was extracted using Trizol reagent and the mRNA levels of the target genes were analyzed using One Step SYBR ${ }^{\circledR}$ PrimeScript $^{\circledR}$ RT-PCR (TaKaRa, China). All primers were synthesized by Sangon Biotech (Shanghai, China) and the sequences were listed in Table 1 . The reaction conditions were as follows: $42^{\circ} \mathrm{C}$ for $5 \mathrm{~min}$, then $95^{\circ} \mathrm{C}$ for $10 \mathrm{~s}$, followed by 40 cycles $(95$ ${ }^{\circ} \mathrm{C}$ for $5 \mathrm{~s}$ and $60{ }^{\circ} \mathrm{C}$ for $31 \mathrm{~s}$ ). $\beta$-actin was used as a control to normalize the relative mRNA levels of all target genes.

Table 1. Primer sequences

\begin{tabular}{|c|c|c|}
\hline Name & Sequences $\left(5^{\prime} \rightarrow 3^{\prime}\right)$ & GenBank No. \\
\hline \multirow[t]{2}{*}{ TAZ } & Forward: CTCCCACTTCAGCTTGG & NM_000116.5 \\
\hline & Reverse: TCTGGTAGACGCCATCTCCT & \\
\hline \multirow[t]{2}{*}{ YAP } & Forward: TAGCCCTGCGATGCCAGTTA & NM_001130145.3 \\
\hline & Reverse: TCATGCTTAGTCCACTGTCTGT & \\
\hline \multirow[t]{2}{*}{ Twist1 } & Forward: GGAGTCCGCAGTCTTACGAG & NM_000474.4 \\
\hline & Reverse: CCAGCTTGAGGGTCTGAATC & \\
\hline \multirow[t]{2}{*}{ Slug } & Forward: GAGCATACAGCCCCATCACT & NM_003068.5 \\
\hline & Reverse: GGGTCTGAAAGCTTGGACTG & \\
\hline \multirow[t]{2}{*}{ SOX-2 } & Forward: TACAGCATGTCCTACTCGCAG & NM_021783.5 \\
\hline & Reverse: GAGGAAGAGGTAACCACA & \\
\hline \multirow[t]{2}{*}{ OCT-4 } & Forward: CTTGAATCCCGAATGGAAAGG & NM_001285987.1 \\
\hline & Reverse: GTGTATATCCCAGGGTGATC & \\
\hline
\end{tabular}




\begin{tabular}{|c|c|c|}
\hline Name & Sequences $\left(5^{\prime} \rightarrow 3^{\prime}\right)$ & GenBank No. \\
\hline \multirow[t]{2}{*}{ E-Cadherin } & Forward: TTGCTACTGGAACAGGGACAC & NM_004360.5 \\
\hline & Reverse: CCCGTGTGTTAGTTCTGCTGT & \\
\hline \multirow[t]{2}{*}{$\mathrm{N}$-Cadherin } & Forward: TTATCCTTGTGCTGATGTTT & NM_001792.5 \\
\hline & Reverse: ТСТТСТТСТССТССАССТТС & \\
\hline \multirow[t]{2}{*}{ Snail1 } & Forward: ТCСТTCGTCCTTCТССТСТАСТT & NM_005985.4 \\
\hline & Reverse: TGTTGCAGTATTTGCAGTTG & \\
\hline \multirow[t]{2}{*}{ Vimenin } & Forward: GAGAACTTTGCCGTTGAAGC & NM_003380.5 \\
\hline & Reverse: TCCAGCAGCTTCCTGTAG & \\
\hline \multirow[t]{2}{*}{ Nanog } & Forward: ACCTTCCAATGTGGAGCAAC & NM_024865.4 \\
\hline & Reverse: GAATTTGGCTGGAACTGCAT & \\
\hline \multirow[t]{2}{*}{ LATS1 } & Forward: GTCCTTCGTGTGGGCTACAT & NM_004690.4 \\
\hline & Reverse: CGAGGATCTTCGGTTGACAT & \\
\hline \multirow[t]{2}{*}{ LATS2 } & Forward: CGCCATACGCCTTTAAGTTC & NM_014572.3 \\
\hline & Reverse: TGGCССТСТTТААССТGTTG & \\
\hline \multirow[t]{2}{*}{ MST1 } & Forward: TTCACGTTTACCTCCGAACC & XM_011533738.3 \\
\hline & Reverse: TGCCACACTTCTCAAАCTGC & \\
\hline \multirow[t]{2}{*}{ MST2 } & Forward: CATGAGGAACAGCAACGAGA & NM_006281.4 \\
\hline & Reverse: TATCACCATGGTCCCCAAGT & \\
\hline \multirow[t]{2}{*}{$\beta$-actin } & Forward: TGACGTGGACATCCGCAAAG & NM_001101.5 \\
\hline & Reverse: CTGGAAGGTGGACAGCGAGG & \\
\hline
\end{tabular}

\section{Co-Immunoprecipitation (Co-IP) assay}

A549 and NCI-H460 cells were treated with CyH at $3.13 \mu \mathrm{M}$ for $16 \mathrm{~h}$. Then, the cells were collected and washed three times with PBS. Afterwards, the washed cells were seeded into six-well plates and incubated with the ice-cold lysis buffer $(200 \sim 400 \mu \mathrm{L} /$ well $)$ on ice for $30 \mathrm{~min}$ with periodic mixing. Afterwards, the cell

A

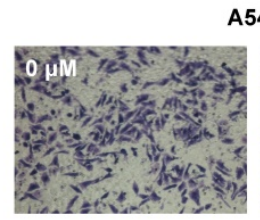

A549
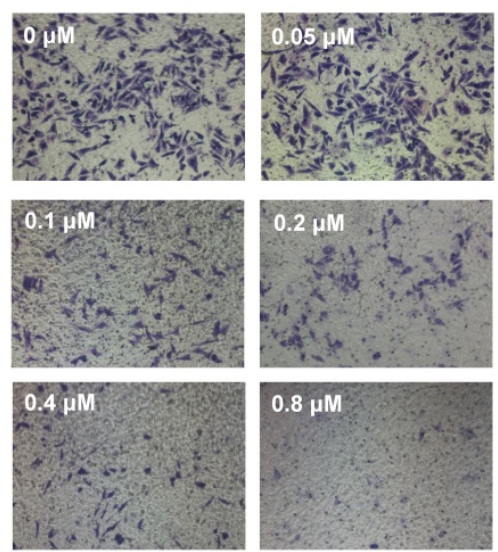

C
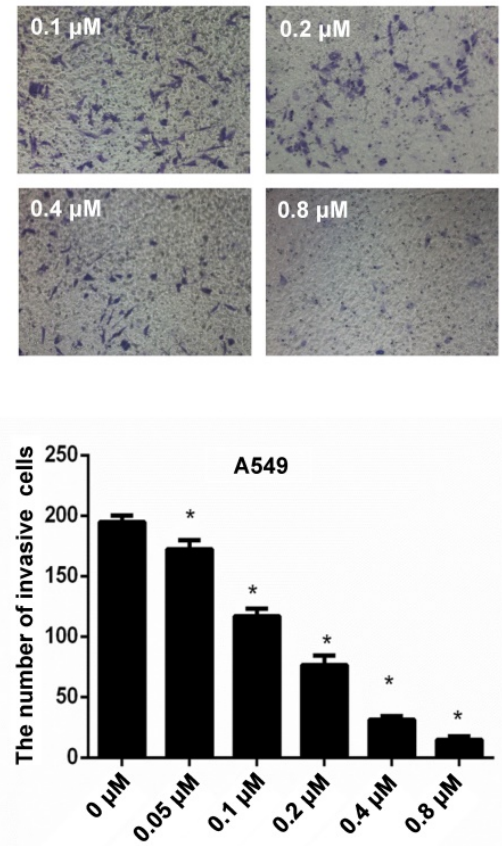

$0.8 \mu \mathrm{M}$

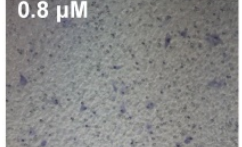

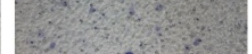

B

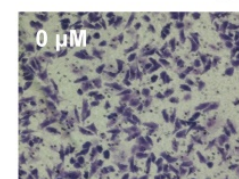

Figure 1. Effect of $\mathrm{CyH}$ on the invasive ability of NSCLC cells. NSCLC cells (A549 and NCI-H460) were plated on the top chambers (Matrigel in the upper chamber) and respectively treated with different concentrations $(0,0.05$, $0.10,0.20,0.4$ and $0.8 \mu \mathrm{M}$ ) of $\mathrm{CyH}$ for $36 \mathrm{~h}$. Afterwards, the number of invasive cells was counted under a microscope. (A,B) The representative results of three independent experiments (A:A549 cells, B:NCl-H460 cells; magnification, $\times 200)$. (C,D) The number of invasive cells. Compared with the control $(0 \mu \mathrm{M}), * P<0.05$. lysates were transferred to a microcentrifuge tube and centrifuged at $4{ }^{\circ} \mathrm{C}(14,000 \mathrm{~g}$ for $15 \mathrm{~min})$. The supernatant was incubated with anti-YAP antibody overnight at $4{ }^{\circ} \mathrm{C}$, and the incubation with rabbit antihuman IgG served as a negative control. Protein A magnetic beads were added into the mixture and incubated with agitation for $2 \mathrm{~h}$ at room temperature. After centrifugation for $30 \mathrm{~s}$ at $14,000 \mathrm{~g}$, the beads (magnetic bead-Ab-Ag complex) were collected and washed three times with PBS for $10 \mathrm{~min}$ each time. The precipitants were dissolved with the SDS loading buffer for the analysis of YAP and TEAD protein expression by western blotting as described above.

\section{Statistical analysis}

All experiments were repeated more than 3 times. All data were shown as $\bar{x} \pm s$. One-way ANOVA assay in SPSS 16.0 statistical software was used to analyze data. $P<0.05$ indicated the statistical significance.

\section{Results}

\section{CyH inhibited invasive ability of NSCLC}

To explore the effect of $\mathrm{CyH}$ on invasive ability of NSCLC cells, A549 and NCI-H460 NSCLC cells were respectively treated with $0,0.05$, $0.1,0.2,0.4$ and $0.8 \mu \mathrm{M}$ of $\mathrm{CyH}$ for $16 \mathrm{~h}$. Our results showed that $\mathrm{CyH}$ inhibited invasion in A549 and NCI-H460 cells (Figure 1A and B), and the number of invasive cells was obviously decreased with the increase of $\mathrm{CyH}$ concentration $(P<0.05$, Figure $1 \mathrm{C}$ and $\mathrm{D})$, indicating that $\mathrm{CyH}$ dosedependently inhibited the invasive ability in NSCLC cells.

\section{CyH inhibited EMT of NSCLC cells}

EMT is an important step of migration and invasion. In our previous study [26] and the present study, we have found that $\mathrm{CyH}$ inhibited migration and invasion in A549 and NCI-H460 NSCLC cells. To further explore the effect of $\mathrm{CyH}$ on EMT, A549 and NCI-H460 cells were respectively treated with 0 , $1.51,3.13,6.25,12.5$, and $25 \mu \mathrm{M}$ of $\mathrm{CyH}$ for $16 \mathrm{~h}$, followed by the analysis of expression of EMTassociated markers. Our results demonstrated that $\mathrm{CyH}$ promoted 
the expression of EMT epithelial marker E-Cadherin (Figure 2A-D, $P<0.05$ ), and inhibited the expression of EMT mesenchymal markers (N-Cadherin and Vimentin) at both protein and mRNA levels in A549 and NCI-H460 cells (Figure 2A-D, $P<0.05$ ). Furthermore, we further found that $\mathrm{CyH}$ dramatically suppressed the expression of EMT transcription factors (Snail1, Slug, and Twist1) in A549 and NCI-H460 cells $(P<0.05$, Figure 3$)$. Taken together, these results suggested that $\mathrm{CyH}$ inhibited EMT of A549 and NCI-H460 cells.

\section{$\mathrm{CyH}$ inhibited the sphere formation and the expression of stemness-related markers in NSCLC cells}

EMT can promote cells with properties of stemness [10], and the sphere formation is one of the important characteristics of stem cells. To further
A

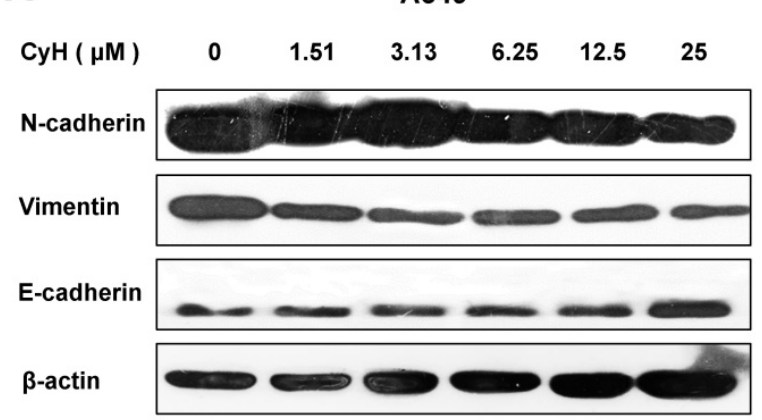

$0 \mu \mathrm{M}$ $1.51 \mu \mathrm{M}$ $3.13 \mu \mathrm{M}$ $6.25 \mu \mathrm{M}$ $12.5 \mu \mathrm{M}$ $25 \mu \mathrm{M}$

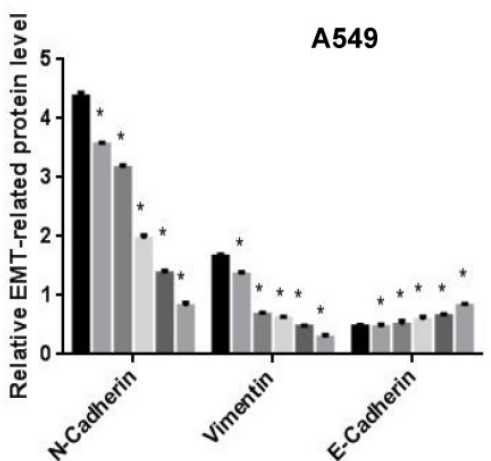

C

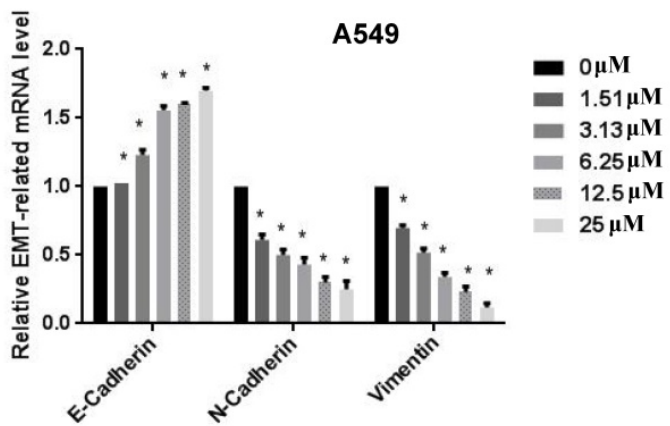

study the effect of $\mathrm{CyH}$ on NSCLC stemness, A549 and NCI-H460 cells were treated with $\mathrm{CyH}$ at $1.51 \mu \mathrm{M}$ for 10 days, followed by the analysis of the sphere formation. Our results showed that $\mathrm{CyH}$ inhibited the sphere formation of A549 and NCI-H460 cells (Figure 4A and B). Moreover, the number of sphere formation $(>100 \mu \mathrm{m})$ was significantly reduced by $\mathrm{CyH}$ treatment $(P<0.05$, Figure 4C) in A549 and NCI-H460 cells. Furthermore, we further studied the effect of $\mathrm{CyH}$ on the expression of stemness-related markers (Sox-2, Oct-4, and Nanog). As expected, $\mathrm{CyH}$ dramatically inhibited Sox-2, Oct-4, and Nanog expression at both protein (Figure 4D and E) and mRNA (Figure $\mathbf{4 F}$ and $\mathbf{G})$ levels $(P<0.05)$. Collectively, $\mathrm{CyH}$ suppressed the stemness of A549 and NCI-H460 cells.

B
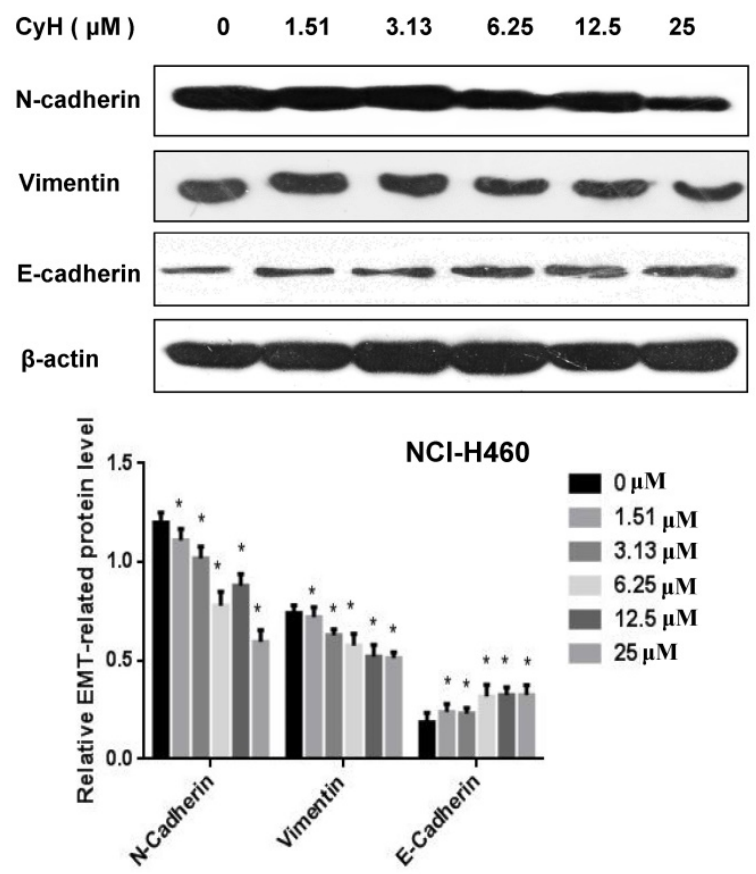

D

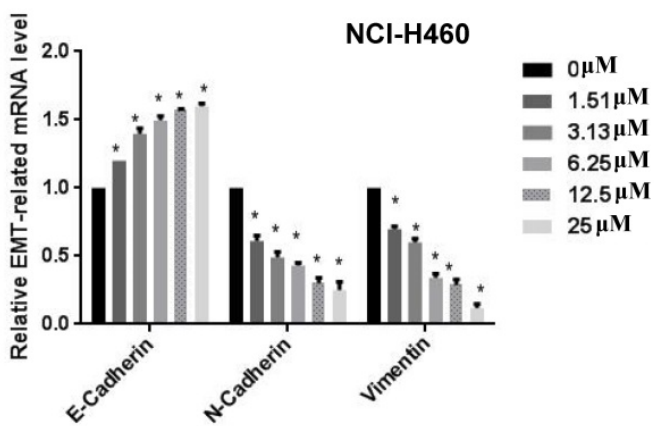

Figure 2. Effect of $\mathrm{CyH}$ on the expression of EMT-related markers in NSCLC cells. NSCLC cells (A549 and NCl-H460) were respectively treated with different concentrations $(0,1.51,3.13,6.25,12.5$ and $25 \mu \mathrm{M})$ of $\mathrm{CyH}$ for $16 \mathrm{~h}$, followed by the analysis of EMT-related marker expression. (A,B) N-Cadherin, Vimentin, and E-Cadherin protein levels were analyzed by western blotting (A:A549 cells, B: NCl-H460 cells; up: the representative results of three independent experiments, down: the results of density for three independent experiments). (C,D) N-Cadherin, Vimentin, and E-Cadherin mRNA levels were determined by RT-qPCR. The results represented the mean \pm SD from three replicate experiments. Compared with control $(0 \mu \mathrm{M}),{ }^{*} \mathrm{P}<0.05$. 
A
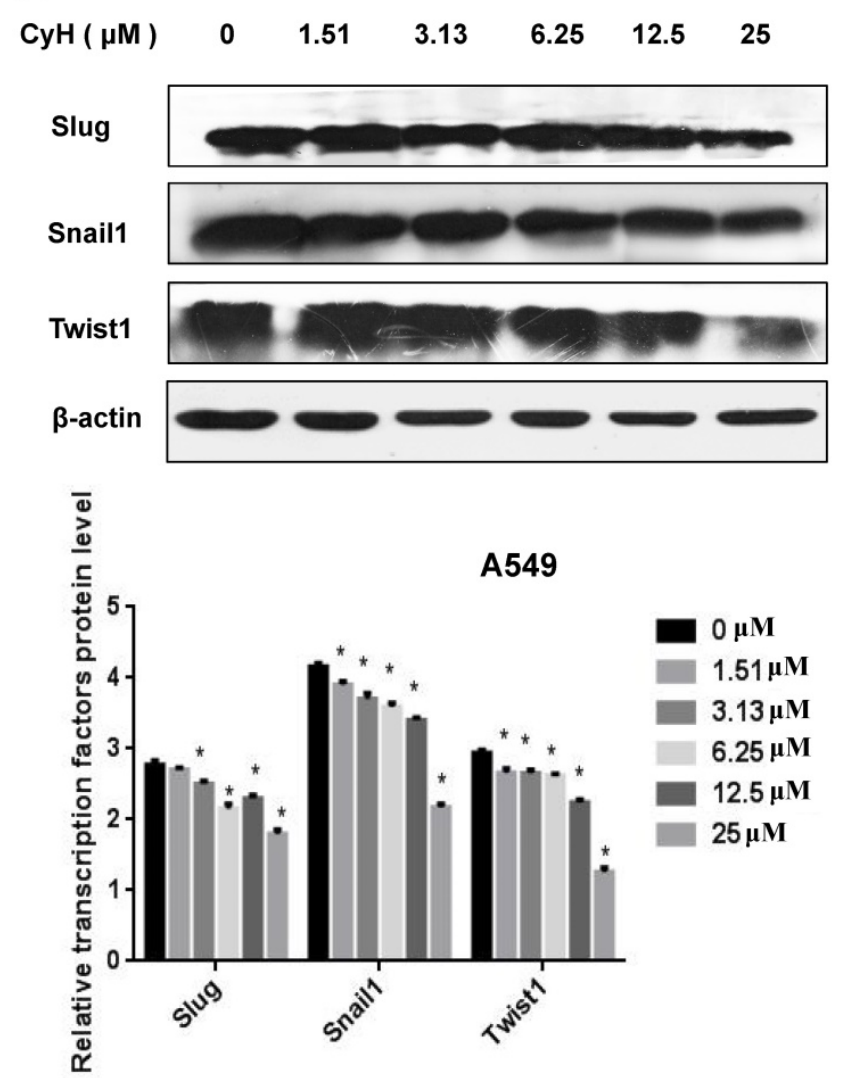

C

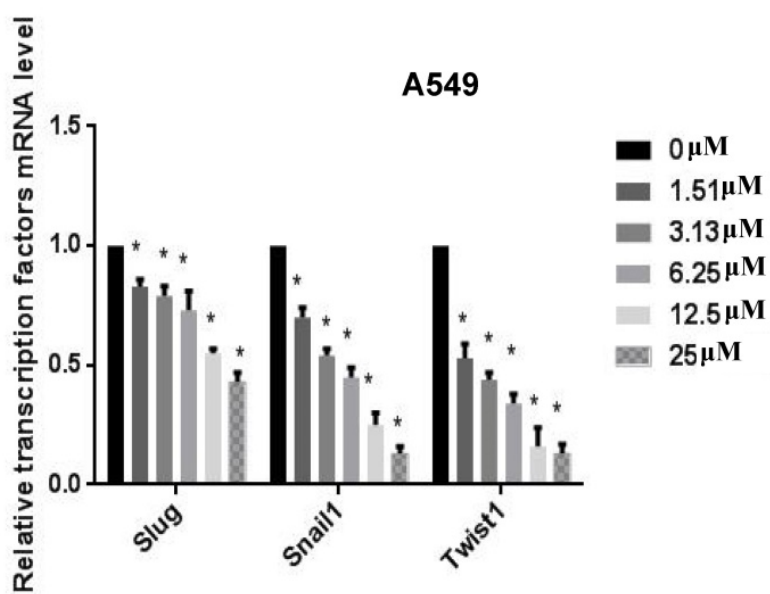

B

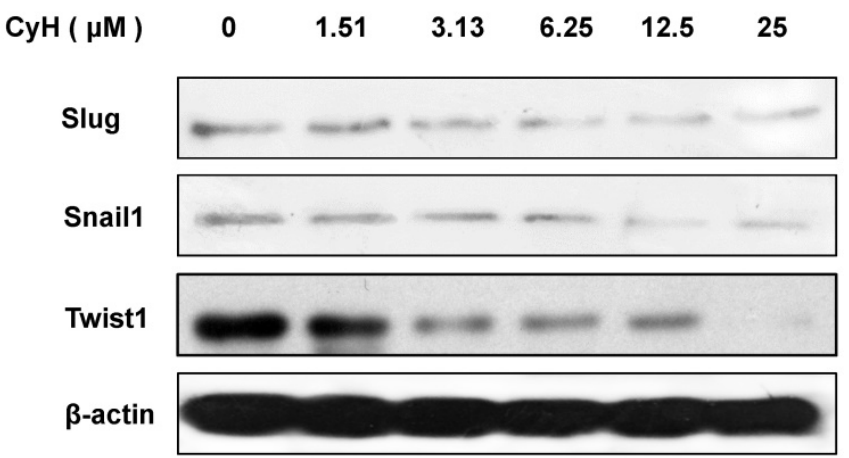

흠

$\mathrm{NCl}-\mathrm{H} 460$

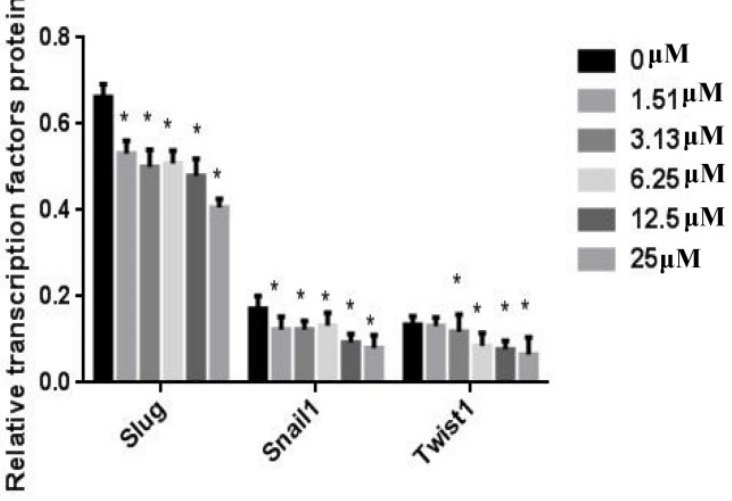

D

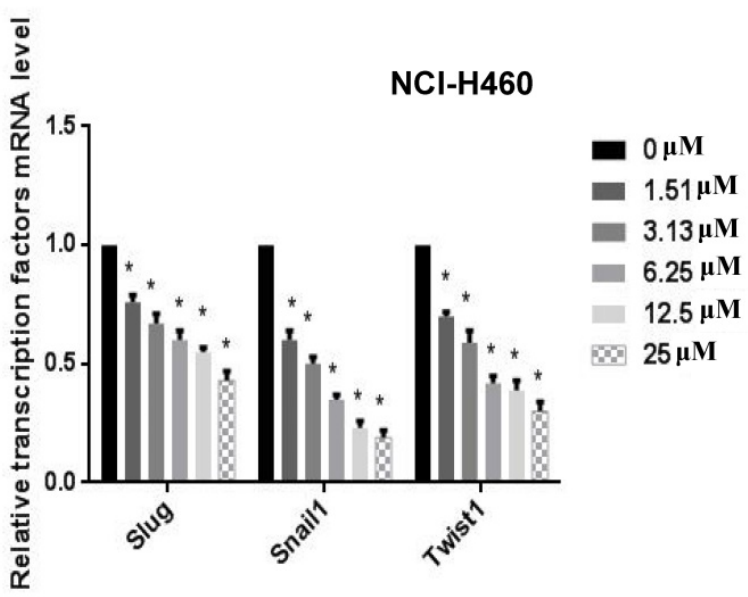

Figure 3. Effect of $\mathrm{CyH}$ on the expression of EMT-related transcription factors in NSCLC cells. NSCLC cells (A549 and NCl-H460) were respectively treated with different concentrations $(0,1.51,3.13,6.25,12.5$ and $25 \mu \mathrm{M})$ of $\mathrm{CyH}$ for $16 \mathrm{~h}$, followed by the analysis of EMT-related transcription factor expression. (A,B) Snail, Slug, and Twist 1 protein levels were analyzed by western blotting (A:A549 cells, B: NCl-H460 cells; up: the representative results of three independent experiments, down: the results of density for three independent experiments). (C,D) Snail1, Slug, Twistl mRNA levels were determined by RT-qPCR. The results represented the mean \pm SD from three replicate experiments. Compared with control $(0 \mu \mathrm{M}),{ }^{*} \mathrm{P}<0.05$.

\section{CyH inhibited EMT through the suppression of YAP/TAZ signaling pathway in NSCLC cells}

YAP/TAZ signaling pathway can mediate EMT and cancer stemness [11-15]. To explore whether $\mathrm{CyH}$ inhibited EMT by suppressing YAP/TAZ signaling pathway, we analyzed YAP, p-YAP, TAZ, LATS1/2, and MST1/2 protein expression by Western blotting.
As shown in Figure 5A and B, YAP and TAZ protein expression was down-regulated and LATS1/2 and MST1/2 protein expression was up-regulated in CyH-treated A549 and NCI-H460 cells. However, $\mathrm{CyH}$ had no obvious effect on the phosphorylation level of YAP in both A549 and NCI-H460 cells. At the same time, LATS1/2, MST1/2, YAP, and TAZ mRNA levels were analyzed by RT-qPCR. As shown in 
Figure 5C and D, CyH significantly down-regulated YAP and TAZ mRNA levels, while CyH remarkably up-regulated LATS1/2 and MST1/2 mRNA levels in A549 and NCI-H460 cells $(P<0.05)$. Moreover, $\mathrm{CyH}$ inhibited the expression of YAP and TEAD proteins

A

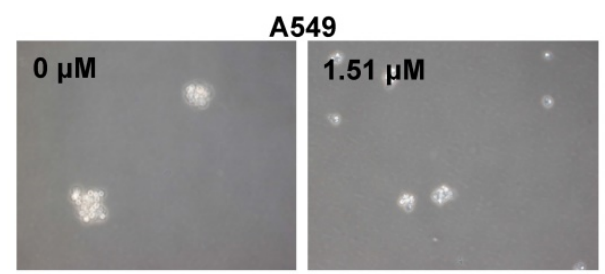

B

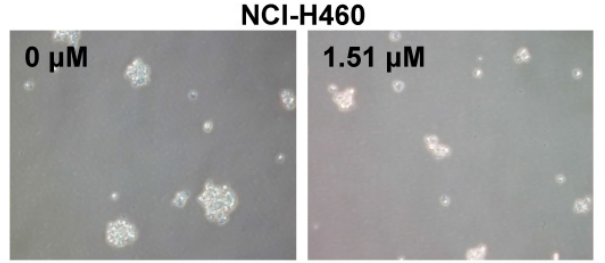

D
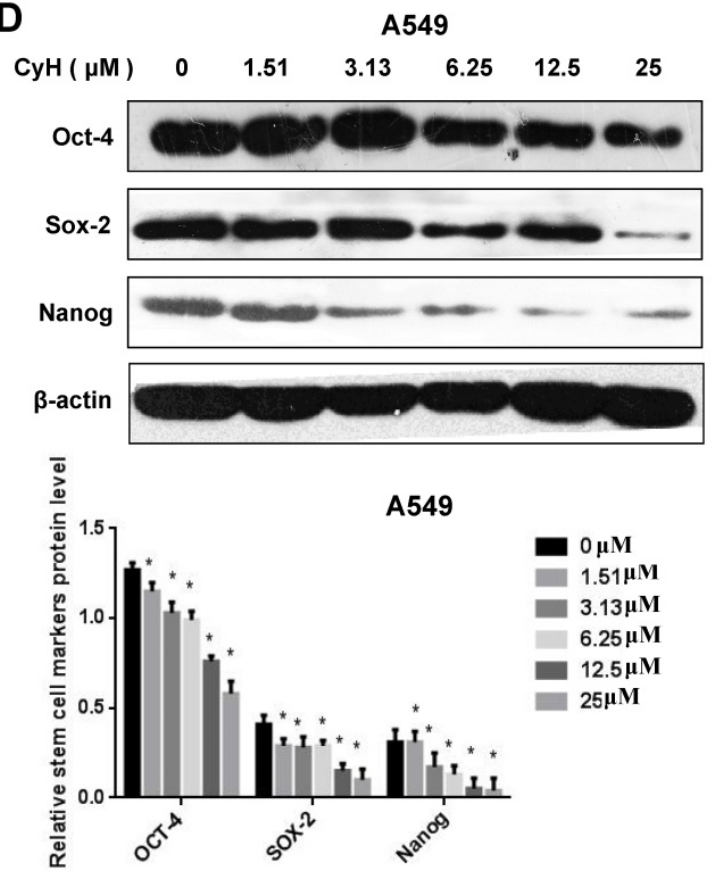

$\mathbf{F}$

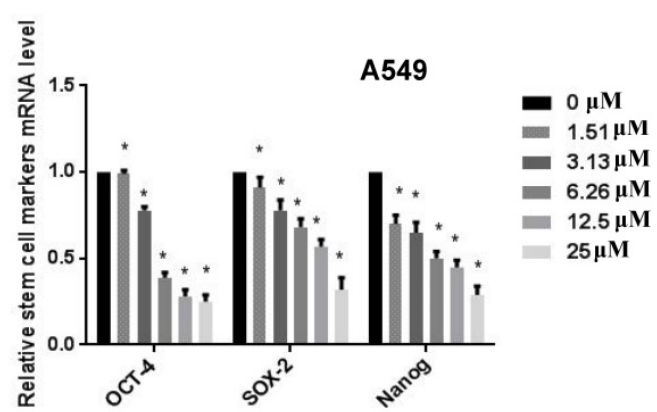

and the interaction between the two proteins in A549 and NCI-H460 cells (Figure 5E). Collectively, these results suggested that $\mathrm{CyH}$ inhibited the activation of YAP/TAZ signaling pathway in NSCLC cells.

C

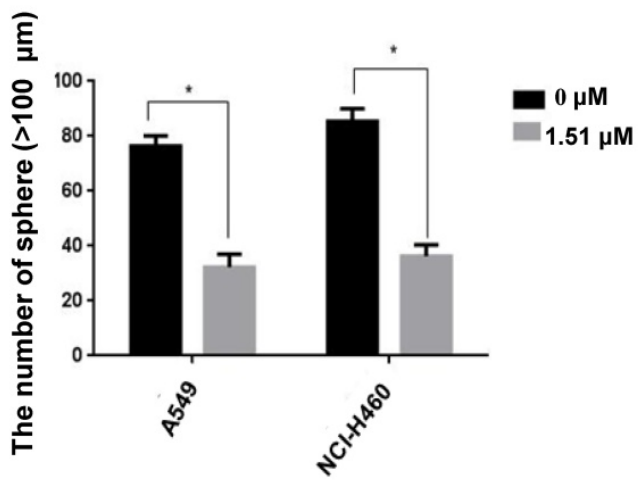

E

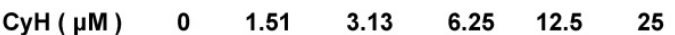
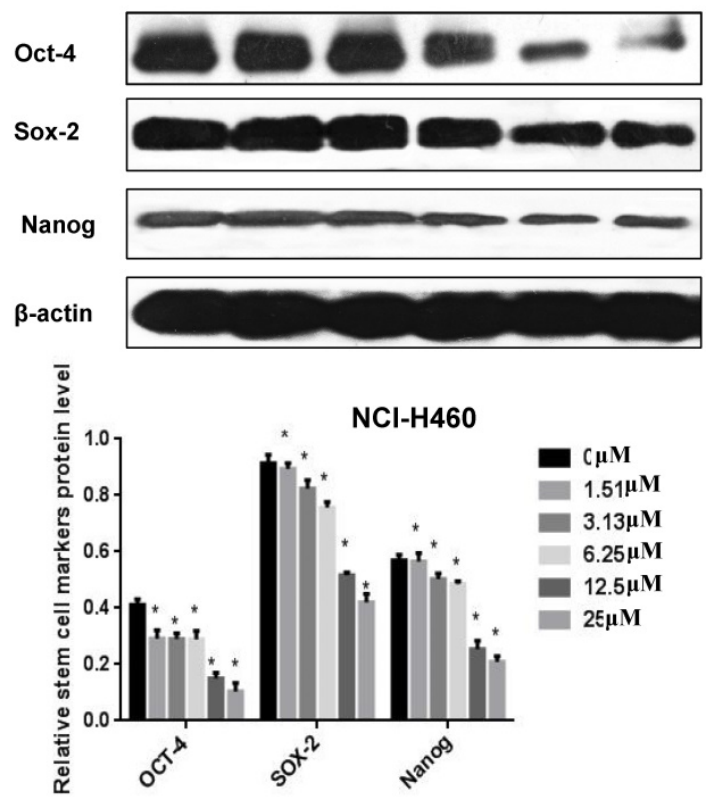

G

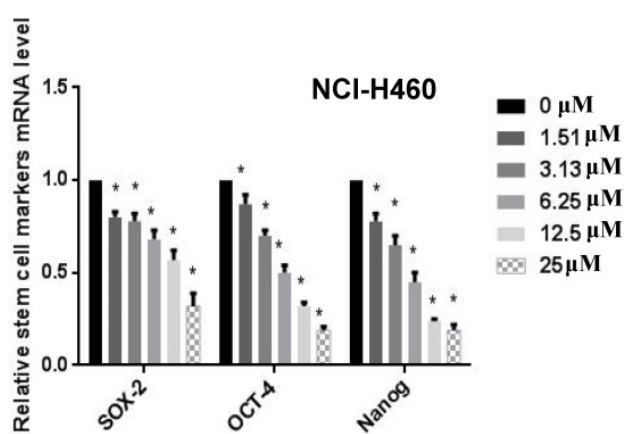

Figure 4. Effect of $\mathrm{CyH}$ on the expression of stemness-related markers in NSCLC cells. (A-C) NSCLC cells were treated with CyH at $1.51 \mu M$ for 10 days. Afterwards, the stem-like sphere formation was observed and the number of spheres was counted under fluorescence microscope (magnification, $\times 200)$. The results are representative of three independent experiments (A:549, B: NCl-H460). The number of stem-like spheres (C). (D,E) NSCLC cells were respectively treated with different concentrations (0, 1.51, 3.13, 6.25, 12.5 and $25 \mu \mathrm{M}$ ) of $\mathrm{CyH}$ for $16 \mathrm{~h}$. Afterwards, OCT-4, SOX-2, and Nanog protein levels were analyzed by western blotting (D:A549 cells, E:NCl-H460 cells; up: the representative results of three independent experiments, down: the results of density for three independent experiments). (F,G) OCT-4, SOX-2, and Nanog mRNA levels were determined by RT-qPCR. All results represented mean \pm SD from three replicate experiments. Compared with control $(0 \mu M),{ }^{*} P<0.05$. 


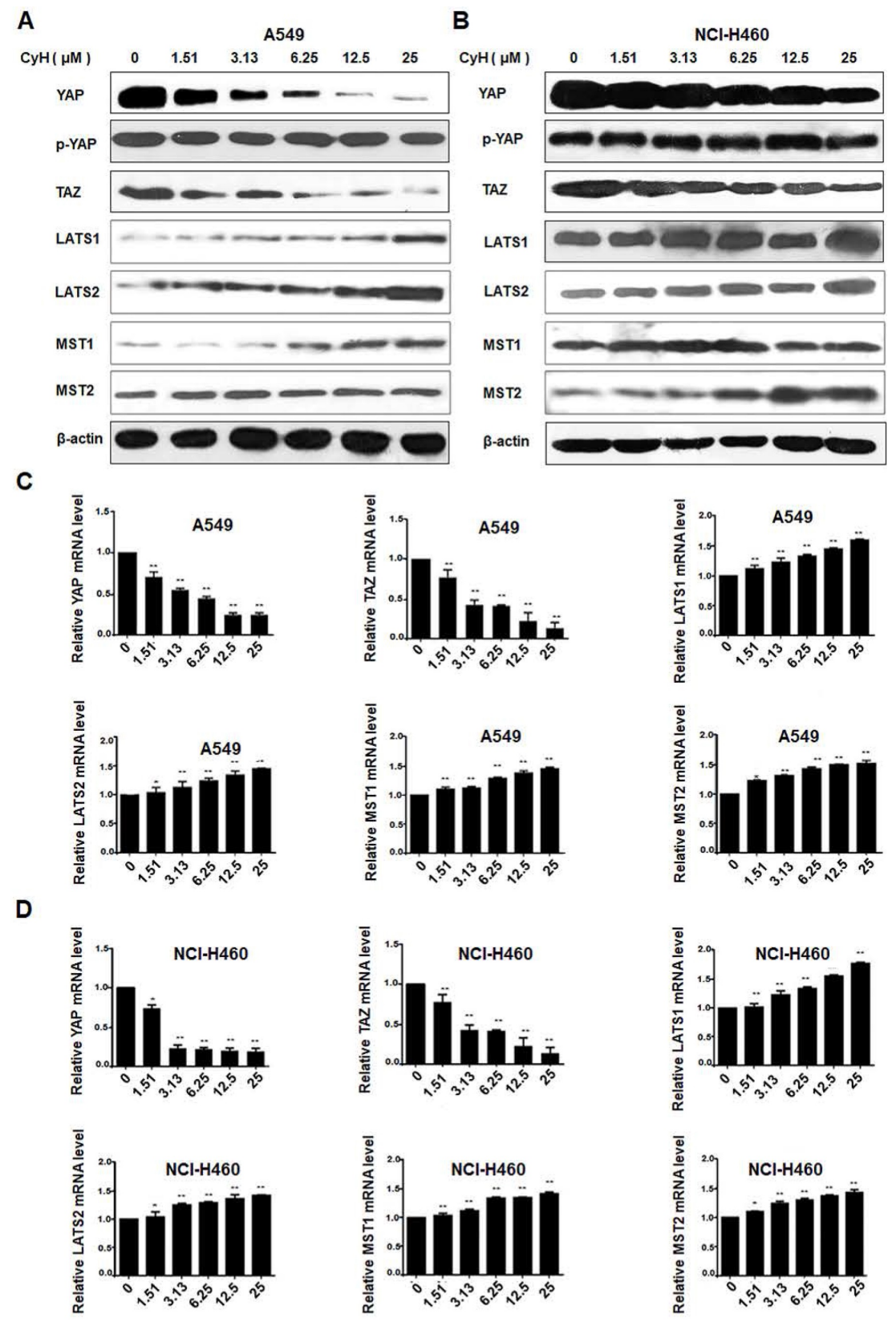

E
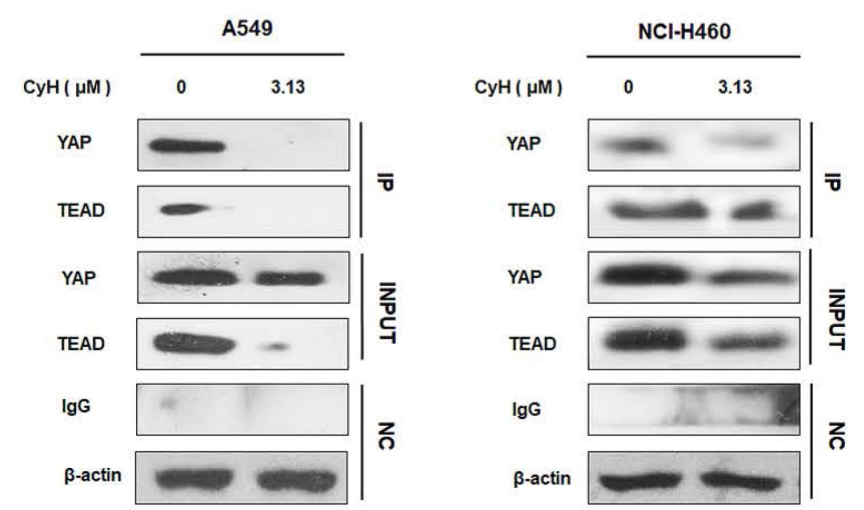

Figure 5. Effect of $\mathrm{CyH}$ on the activation of YAP/TAZ signaling pathway in NSCLC cells. NSCLC cells (A549 and $\mathrm{NCl}-\mathrm{H} 460)$ were respectively treated with different concentrations $(0,1.51,3.13,6.25,12.5$ and $25 \mu \mathrm{M})$ of $\mathrm{CyH}$ for $16 \mathrm{~h}$, followed by the analysis of expression of YAP/TAZ signaling-related factors. (A,B) YAP, P-YAP, TAZ, LATS1/2, and MST1/2 protein levels were analyzed by western blotting (A:A549 cells, B:NCI-H460 cells). (C,D) YAP, P-YAP, TAZ, LATS1/2, and MST1/2 mRNA levels were determined by RT-qPCR. The results represented mean $\pm S D$ from three replicate experiments. Compared with control $(0 \mu M),{ }^{*} P<0.05,{ }^{* *} P<0.01$. (E) The interaction between YAP and TEAD was detected by co-immunoprecipitation.
To further validate the role of YAP/TAZ signaling pathway in the effect of $\mathrm{CyH}$ on EMT and cancer stemness, A549 and NCI-H460 cells were transiently transfected with YAP-siRNA, followed by the analysis for EMT-related protein expression. Our results showed that YAP-siRNA obviously knocked down the expression of YAP (Figure 6A). As expected, the knockdown of YAP inhibited the effect of $\mathrm{CyH}$ on the expression of EMT-related proteins including N-Cadherin, Vimentin, and E-Cadherin and stemness-related proteins including OCT-4, SOX-2, and Nanog (Figure 6B and $C)$.

\section{Discussion}

Cytochalasins are a sort of microfilament-directed agents [28]. Recently, a growing body of evidence has demonstrated that cytochalasins also exhibit potential anticancer activities both in vitro and in vivo [29-32]. In our previous studies, we isolated $\mathrm{CyH}$, one kind of cytochalasins, from endophytic fungus Phomopsis sp. derived from mangrove, and found that $\mathrm{CyH}$ could induce apoptosis and inhibit migration in A549 NSCLC cells [26]. In the present study, we further found that $\mathrm{CyH}$ dose-dependently inhibited invasion in A549 and NCI-H460 NSCLC cells (Figure 1). In our previous studies, we demonstrated that $\mathrm{CyH}$ suppressed NSCLC angiogenesis by inhibiting hypoxia inducible factor (HIF)-1a protein accumulation and vascular endothelial growth factor (VEGF) expression [27]. EMT is a key step of migration and invasion. Moreover, HIFs were considered as the master regulators of stemness properties, and VEGF-mediated angiogenesis was reported to be associated with EMT-induced cancer stemness [33-35]. Therefore, in the present study, we further investigated the effect of $\mathrm{CyH}$ on EMT and cancer stemness of NSCLC. Our results showed that $\mathrm{CyH}$ inhibited EMT 
(Figures 2 and 3). Additionally, we also found that $\mathrm{CyH}$ significantly down-regulated the expression of Oct-4, Sox-2, and Nanog, the stemness-related markers (Figure 4D-G). Furthermore, we demonstrated that $\mathrm{CyH}$ at $1.51 \mu \mathrm{M}$ significantly inhibited sphere formation (Figure 4A-C). Collectively, our results indicate that $\mathrm{CyH}$ suppresses EMT and cancer stemness in NSCLC cells, suggesting that $\mathrm{CyH}$ may be a potential chemotherapeutic agent in NSCLC therapy.

A

B
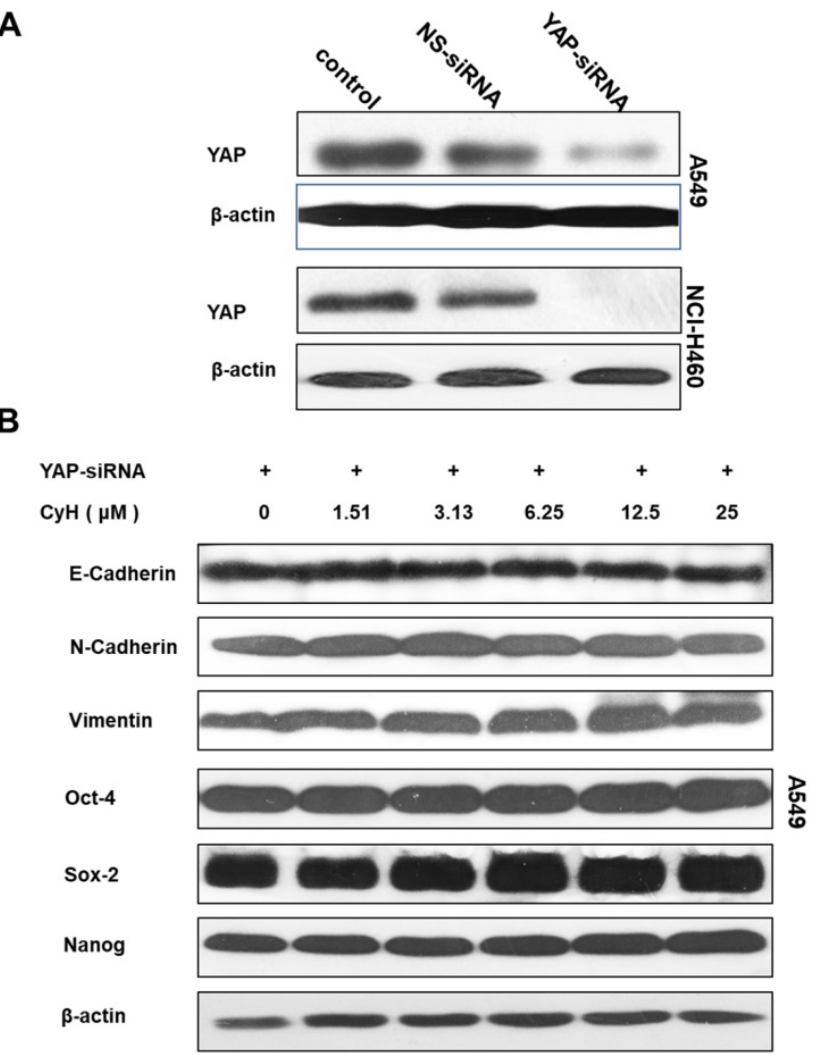

C

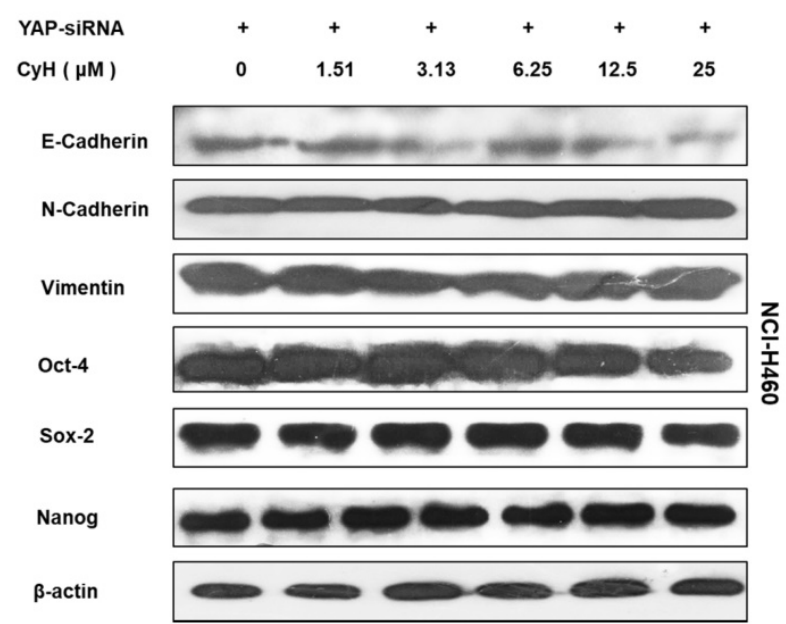

Figure 6. Role of YAP in the effect of $\mathrm{CyH}$ on EMT- and stemness-related protein expression. (A-C) NSCLC cells were transiently transfected with YAP-siRNA and respectively treated with different concentrations $(0,1.51,3.13,6.25,12.5$ and $25 \mu \mathrm{M})$ of $\mathrm{CyH}$ for $16 \mathrm{~h}$, followed by Western blotting. The expression of YAP (A) and the expression of E-cadherin, N-cadherin, Vimentin, OCT-4, SOX-2, and Nanog (B:A549, $\mathrm{C}: \mathrm{NCl}-\mathrm{H} 460)$
YAP/TAZ signaling pathway can regulate EMT and cancer stemness. YAP was found to regulate the EMT-associated genes by inducing SOX-2 expression in cooperation with Oct-4 in NSCLC cells [12] and to directly up-regulate SOX-9 and induce stem-like properties in esophageal cancer cells [13]. TAZ was demonstrated to promote cancer stem cell (CSC) traits in breast cancer cells [14], and overexpression of TAZ in mammary epithelial cells was reported to induce EMT [15]. Moreover, TAZ was found to be essential for metastasis and chemo-resistance of breast cancer stem cells [36]. These reports indicate that YAP/TAZ signaling pathway can promote tumor initiation, progression, and metastasis by mediating EMT and cancer stemness. Interestingly, YAP/TAZ was regarded as an important target for the prevention and treatment of NSCLC $[18,21]$. Therefore, in the present study, we further explore the effect of $\mathrm{CyH}$ on the YAP/TAZ signaling pathway. Our results showed that $\mathrm{CyH}$ dramatically inhibited YAP and TAZ expression but had no obvious effect on YAP phosphorylation, indicating that $\mathrm{CyH}$ downregulated dephosphorylated YAP and TAZ levels. MST1/2 and LATS1/2, the upstream core kinases of $\mathrm{YAP} / \mathrm{TAZ}$, are tumor inhibitors that can suppress the oncogenic nuclear function of YAP/TAZ and TEAD [37]. Here, we further analyze the effect of $\mathrm{CyH}$ on MST1/2 and LATS1/2 expression. Our results showed that $\mathrm{CyH}$ dramatically promoted the expression of MST1, MST2, LATS1, and LATS2 (Figure 5A-D, $P<0.05)$. YAP-TEAD interaction can promote tumor growth and metastasis [17], and YAP/TAZ-TEAD transcriptional complex has been demonstrated to be a potential target for cancer therapy [38-40]. So, we further analyze the effect of $\mathrm{CyH}$ on the interaction between YAP and TEAD in this study. As expected, in the present study, we demonstrated that the interaction between YAP and TEAD was significantly attenuated by $\mathrm{CyH}$ treatment (Figure 5E). Collectively, these results suggest that $\mathrm{CyH}$ can inhibit the activation of YAP/TAZ signaling pathway.

To further verify whether $\mathrm{CyH}$ inhibited EMT and cancer stemness in NSCLC cells via the YAP/TAZ signaling pathway, YAP-siRNA was transfected into NSCLC cells. Our results showed that YAP knockdown abrogated the effect of $\mathrm{CyH}$ on the expression of EMT- and cancer stemness-related markers (Figure 6), suggesting that YAP/TAZ pathway may be involved in the effect of $\mathrm{CyH}$ on EMT and cancer stemness in NSCLC cells.

In summary, in the present study, we firstly demonstrated that $\mathrm{CyH}$ inhibited EMT and cancer stemness in A549 and NCI-H460 cells. Moreover, YAP/TAZ signaling pathway was involved in 
mediating this process. These results indicate that $\mathrm{CyH}$ may be a potential chemotherapeutic agent for NSCLC and provide a novel molecular mechanism for the role of $\mathrm{CyH}$ in the prevention and treatment of NSCLC.

\section{Acknowledgements}

This work was supported by the grants from National Natural Science Foundation of China (81372511); Guangdong Basic and Applied Basic Research Foundation (2017A030313539 and 2019A1515011081); "Sail plan" in Guangdong Province to cultivate high-level talents (201635011); "Group-type" Special Supporting Project for Educational Talents in Universities (4SG19210G); Competitive Allocation of Special Funds for Science and Technology Development in Zhanjiang (2018A01041); and Key Cultivation Project of Guangdong Medical University (GDMUZ201804).

\section{Competing Interests}

The authors have declared that no competing interest exists.

\section{References}

1. Bray F, Ferlay J, Soerjomataram I, et al. Global cancer statistics 2018: GLOBOCAN estimates of incidence and mortality worldwide for 36 cancers in 185 countries. CA Cancer J Clin. 2018; 68: 394-424.

2. Demicheli R, Fornili M, Ambrogi F, et al. Recurrence dynamics for non-small-cell lung cancer: effect of surgery on the development of metastases. J Thorac Oncol. 2012; 7: 723-30.

3. Lee K, Kim HR, Kim DK, et al. Post-recurrence survival analysis of stage I non-small-cell lung cancer. Asian Cardiovasc Thorac Ann. 2017; 25: 623-9.

4. Mittal V. Epithelial Mesenchymal Transition in Tumor Metastasis. Annu Rev Pathol. 2018; 13: 395-412.

5. Otsuki Y, Saya H, Arima Y. Prospects for new lung cancer treatments that target EMT signaling. Dev Dyn. 2018; 247: 462-72.

6. Song J, Wang W, Wang Y, et al. Epithelial-mesenchymal transition markers screened in a cell-based model and validated in lung adenocarcinoma. BMC Cancer. 2019; 19: 680 .

7. Zhang $\mathrm{W}, \mathrm{Wu} \mathrm{X}, \mathrm{Hu} \mathrm{L}$, et al. Overexpression of Human Papillomavirus Type 16 Oncoproteins Enhances Epithelial-Mesenchymal Transition via STAT3 Signaling Pathway in Non-Small Cell Lung Cancer Cells. Oncol Res. 2017; 25: 843-52.

8. Lafuente-Sanchis A, Olmo A, Carretero J, et al. Clinical significance of epithelial-mesenchymal transition-related markers expression in the micrometastatic sentinel lymph node of NSCLC. Clin Transl Oncol. 2020; 22: 381-91.

9. Matsubara T, Tagawa T, Takada K, et al. Clinical and Prognostic Significance of the Epithelial-Mesenchymal Transition in Stage IA Lung Adenocarcinoma: A Propensity Score-Matched Analysis. Clin Lung Cancer. 2019; 20: e504-13.

10. Mani SA, Guo W, Liao M-J, et al. The epithelial-mesenchymal transition generates cells with properties of stem cells. Cell. 2008; 133: 704-15.

11. Cheng D, Jin L, Chen Y, et al. YAP promotes epithelial mesenchymal transition by upregulating Slug expression in human colorectal cancer cells. Int J Clin Exp Pathol. 2020; 13(4):701-710.

12. Bora-Singhal N, Nguyen J, Schaal C, et al. YAP1 Regulates OCT4 Activity and SOX2 Expression to Facilitate Self-Renewal and Vascular Mimicry of Stem-Like Cells. Stem Cells. 2015; 33: 1705-18.

13. Song S, Ajani JA, Honjo S, et al. Hippo coactivator YAP1 upregulates SOX9 and endows esophageal cancer cells with stem-like properties. Cancer Res. 2014; 74: 4170-82.

14. Cordenonsi M, Zanconato F, Azzolin L, et al. The Hippo transducer TAZ confers cancer stem cell-related traits on breast cancer cells. Cell. 2011; 147: $759-72$

15. Lei QY, Zhang H, Zhao B, et al. TAZ promotes cell proliferation and epithelial-mesenchymal transition and is inhibited by the hippo pathway. Mol Cell Biol. 2008; 28: 2426-36.

16. Dong $\mathrm{X}$, Meng L, Liu P, et al. YAP/TAZ: a promising target for squamous cell carcinoma treatment. Cancer Manag Res. 2019; 11: 6245-52.
17. Lamar JM, Stern P, Liu H, et al. The Hippo pathway target, YAP, promotes metastasis through its TEAD-interaction domain. Proc Natl Acad Sci USA. 2012; 109: E2441-50.

18. Zhang $\mathrm{X}$, Zhao $\mathrm{H}, \mathrm{Li} \mathrm{Y}$, et al. The role of $\mathrm{YAP} / \mathrm{TAZ}$ activity in cancer metabolic reprogramming. Mol Cancer. 2018; 17: 134.

19. Shibata M, Ham K, Hoque MO. A time for YAP1: Tumorigenesis, immunosuppression and targeted therapy. Int J Cancer. 2018; 143: 2133-44.

20. Warren JSA, Xiao Y, Lamar JM. YAP/TAZ Activation as a Target for Treating Metastatic Cancer. Cancers (Basel). 2018; 10: E115.

21. Lo Sardo F, Strano S, Blandino G. YAP and TAZ in Lung Cancer: Oncogenic Role and Clinical Targeting. Cancers (Basel). 2018; 10: E137.

22. Deshmukh SK, Gupta MK, Prakash V, et al. Mangrove-Associated Fungi: A Novel Source of Potential Anticancer Compounds. J Fungi (Basel). 2018; 4: E101.

23. Chen Y, Liu Z, Huang Y, et al. Ascomylactams A-C, Cytotoxic 12- or 13-Membered-Ring Macrocyclic Alkaloids Isolated from the Mangrove Endophytic Fungus sp. CYSK-4, and Structure Revisions of Phomapyrrolidones A and C. J Nat Prod. 2019; 82: 1752-58.

24. Deshmukh SK, Prakash V, Ranjan N. Marine Fungi: A Source of Potential Anticancer Compounds. Front Microbiol. 2017; 8: 2536.

25. Kharwar RN, Mishra A, Gond SK, et al. Anticancer compounds derived from fungal endophytes: their importance and future challenges. Nat Prod Rep. 2011; 28: 1208-28.

26. Ma Y, Wu X, Xiu Z, et al. Cytochalasin $\mathrm{H}$ isolated from mangrove-derived endophytic fungus induces apoptosis and inhibits migration in lung cancer cells. Oncol Rep. 2018; 39: 2899-905.

27. Ma Y, Xiu Z, Zhou Z, et al. Cytochalasin H Inhibits Angiogenesis the Suppression of HIF-1a Protein Accumulation and VEGF Expression through PI3K/AKT/P70S6K and ERK1/2 Signaling Pathways in Non-Small Cell Lung Cancer Cells. J Cancer. 2019; 10: 1997-2005.

28. Liu J, Huang B, Xiu Z, et al. PI3K/Akt/HIF-1a signaling pathway mediates HPV-16 oncoprotein-induced expression of EMT-related transcription factors in non-small cell lung cancer cells. J Cancer. 2018; 9: 3456-3466.

29. Trendowski M. Using cytochalasins to improve current chemotherapeutic approaches. Anticancer Agents Med Chem. 2015; 15: 327-35.

30. Heidarzadeh S, Motalleb GH, Zorriehzahra MJ. Evaluation of Tumor Regulatory Genes and Apoptotic Pathways in The Cytotoxic Effect of Cytochalasin H on Malignant Human Glioma Cell Line (U87MG). Cell J. 2019; 21: 62-9.

31. Wang WX, Li ZH, et al. Cytotoxic cytochalasans from fungus Xylaria longipes. Fitoterapia. 2019; 137: 104278.

32. $\mathrm{Yi} \mathrm{JM}, \mathrm{Kim}$ J, Park JS, et al. In vivo Anti-tumor Effects of the Ethanol Extract of Gleditsia sinensis Thorns and Its Active Constituent, Cytochalasin H. Biol Pharm Bull. 2015; 38: 909-12.

33. Fantozzi A, Gruber DC, Pisarsky L, et al. VEGF-mediated angiogenesis links EMT-induced cancer stemness to tumor initiation. Cancer Res. 2014; 74: 1566-75.

34. Mimeault M, Batra SK. Hypoxia-inducing factors as master regulators of stemness properties and altered metabolism of cancer- and metastasis-initiating cells. J Cell Mol Med. 2013; 17: 30-54.

35. Xu MH, Gao X, Luo D, et al. EMT and acquisition of stem cell-like properties are involved in spontaneous formation of tumorigenic hybrids between lung cancer and bone marrow-derived mesenchymal stem cells. PLoS ONE. 2014; 9: e87893.

36. Bartucci M, Dattilo R, Moriconi $\mathrm{C}$, et al. TAZ is required for metastatic activity and chemoresistance of breast cancer stem cells. Oncogene. 2015; 34: 681-90.

37. Park JH, Shin JE, Park HW. The Role of Hippo Pathway in Cancer Stem Cell Biology. Mol Cells. 2018; 41: 83-92.

38. Santucci M, Vignudelli $\mathrm{T}$, Ferrari $\mathrm{S}$, et al. The Hippo Pathway and YAP/TAZ-TEAD Protein-Protein Interaction as Targets for Regenerative Medicine and Cancer Treatment. J Med Chem. 2015; 58: 4857-73.

39. Crawford JJ, Bronner SM, Zbieg JR. Hippo pathway inhibition by blocking the YAP/TAZ-TEAD interface: a patent review. Expert Opin Ther Pat. 2018; 28: 867-73.

40. Pobbati AV, Hong W. A combat with the YAP/TAZ-TEAD oncoproteins for cancer therapy. Theranostics. 2020;10(8):3622-35. 